\title{
Editorial
}

\section{Medical Anthropology of the Middle East?}

In a region in which everyday life is under different kinds of threat, issues related to health are of prime importance. Preserving life, which is the least human right to be respected, is the last resort, yet it seems human life is an insignificant matter. For example, in everyday discourse in Tehran, we often hear, "Human life doesn't count." Within this local world view the opposite can also be observed: an obsessive preoccupation with aesthetic aspects of the human body (see $A M E$, vol. 1, no. 1). In between lies all that can be studied by medical anthropologists.

Is anthropology of the Middle East attending to the variety of problems posed within this domain? Medical anthropology is concerned with the application of anthropology to achieve a better understanding of health, illness and healing. Whether the professionals of the field come from medicine or anthropology, they conduct research in diverse human settings, from urban hospitals and clinics to rural areas and pastoral nomadic societies.

Medical anthropology critically studies the socio-political economy of health. It looks at priorities and trends in biomedical and public health research and can assess the role of health-related programmes for all parts of the population. It also examines the fundamental relationship between the science of medicine, including its presence, the states of mind it produces and the expectations it creates, and traditional meanings of health, disease and healing.

The kinship traditions within which life in the Middle East was formerly conducted provided constant care and optimal support for the newly born and the elderly. Modern life, with its priority on individualism and individual households, professionalism and a willingness to move to different locations at any time, is not necessarily producing the best setting for those who need daily protection and care. Replacements for these resources are acutely in demand, and the interim period has been passing with great distress. Realising that there is more to health and disease than physical and biological processes, and given that over 80 per cent of health problems are attributable to behaviour and the environment in which people live, medical anthropology has claimed 
considerable viable grounds for its existence. But are these grounds utilised in research conducted in the Middle Eastern region?

In specific areas such as vaccination, birth control and in vitro fertilisation, as well as AIDS prevention and treatments, significant developments have been made in certain countries. However, other areas of research have not yet come under scrutiny, for instance, the place of health insurance and its correct use, its sufficiency, the change it has brought about in kin relations and many others. The medical pluralism which has been produced by dualistic systems (i.e. bio-Western medicine versus ethno-traditional systems) of thinking and behaviour towards health, disease and healing needs enormous and immediate attention. How are people affected by the duality of these systems? How are they integrating them and where do we see a success in their integration? Or are these people left in the abyss?

In order to find responses to these and many other viable questions, we have tried to open the pages of medical anthropology in $A M E$ - pages that will remain open for a number of future issues until we have covered this area, which is rich in traditional medicine (ethno-medicine), with names such as Farabi, Jorjani and Abu Ali Sina, yet also pursues the latest technological developments in the fields of medicine and public health. And what does the study of everyday life tell us when health and health-related subjects are investigated empirically? This is our focus in medical anthropology, as the articles of this issue illustrate.

- Soheila Shahshahani and Mohammad Shahbazi 